\title{
Effect of consolidation on the flexural creep behaviour of all-polypropylene composite
}

\author{
A. Izer, T. Bárány* \\ Department of Polymer Engineering, Budapest University of Technology and Economics, H-1111 Budapest, \\ Múegyetem rkp. 3., Hungary
}

Received 21 December 2009; accepted in revised form 3 February 2010

\begin{abstract}
The long-term viscoelastic behaviour of self-reinforced polypropylene composites (SRPPC) was studied by short-term flexural creep tests at different temperatures. As reinforcement a fabric, woven from highly stretched split PP yarns, whereas as matrix materials $\alpha$ and $\beta$ crystal forms of isotactic PP homopolymer and random copolymer (with ethylene) were selected and used. The composite sheets were produced by film-stacking method and compression moulded at different processing temperatures $\left(5,20,35^{\circ} \mathrm{C}\right.$ above the melting temperatures of the matrices) keeping the holding time and pressure constant. The manufactured specimens were subjected to isothermal creep tests at different temperatures ranging from -20 to $80^{\circ} \mathrm{C}$ under an applied load. The time-temperature superposition principle was verified for the creep data. An Arrhenius type relationship described the shift data obtained from the creep tests. It was found, that with improving consolidation (increasing processing temperature) the creep compliance decreased and good correlation was found between creep compliance and density/peel strength.
\end{abstract}

Keywords: polymer composites, self-reinforced composite, PP, creep

\section{Introduction}

Under steady loading components (especially polymers at room temperature) can slowly deform, a phenomenon called creep. When a plastic material is loaded with a constant load, it deforms continuously with time. This time dependent behaviour of materials (viscoelasticity) is an important characteristic of polymers. To know this long-term behaviour of polymers is essential to estimate their life-time under load. Although creep in an anisotropic, multi-phase system, like composites, is very complex, the analysis of creep properties is important for the use of composites in long-term applications. This may be more significant in selfreinforced polymer composites than in classic materials reinforced by glass or basalt fibre, where not only the matrix but the reinforcement is made of polymer. Note that in comparison to the classical composites self-reinforced composites have some advantages in addition to the good mechanical properties: easy and fully recyclability and low density (the same as those of the matrix materials) [1-8].

Earlier works have shown that the creep behaviour of PP fibre reinforced PP composites depends strongly on stress, temperature, void content, and fibre loading [9-11]. It was concluded, that creep resistance decreases if temperature or stress rises. Several other studies investigated the influence of adhesion and density of the composites on the creep behaviour [12-14]. With increasing consolidation (lower void content) the resistance to creep increases.

The great drawback of the creep test is the long time requirement. But a number of observations suggest that the effects of time and temperature are 
equivalent $[15,16]$. The influence of high temperature and long time has similar effect on the polymer material. With shifting the single creep curves (measured at different testing temperatures) together (to a selected reference temperature) a master curve can be created. This time-temperature superposition method (TTS) is able to predict the long-term properties of the material from short time creep tests at higher temperature [17-19]. The relation between temperature and the shift factor can generally be described by the Arrhenius Equation (1):

$$
\ln a_{T}=\frac{E}{R}\left(\frac{1}{T}-\frac{1}{T_{0}}\right)
$$

where $a_{T}$ is the horizontal shift factor, $R$ is the universal gas constant, $E$ is the activation energy, $T_{0}$ is the reference temperature and $T$ is the experimental temperature. The Arrhenius equation relates the horizontal shift factor with temperature [20].

Another commonly used empirical equation for TTS that relates a shift in temperature with a shift in time is the Williams-Landel-Ferry (WLF) Equation (2):

$$
\ln a_{T}=-\frac{C_{1}\left(T-T_{0}\right)}{C_{2}+\left(T-T_{0}\right)}
$$

where $C_{1}$ and $C_{2}$ are constants, and $T$ and $T_{0}$ are the experimental and reference temperatures. The WLF equation was found empirically to describe the frequency dependence of glass transition temperature in amorphous polymers [20].

In this work, the effect of consolidation of the selfreinforced composite on the creep behaviour was investigated. The applicability of TTS principle to short term creep data was verified in order to predict the long-term creep response of SRPPC.

\section{Materials, their processing and testing}

\subsection{Materials}

A plain woven fabric (Stradom S. A., Czestochowa, Poland) composed of highly stretched split PP tapes with a nominal weight of $180 \mathrm{~g} / \mathrm{m}^{2}$ (the thickness is approximately $180 \mu \mathrm{m}$ ) was selected and used as reinforcement. The reinforcing tape has a melting temperature of $T_{m}=172.4^{\circ} \mathrm{C}$ (determined by DSC), and a tensile strength of $465 \pm 32 \mathrm{MPa}$ (measured on a single tape).
Three kinds of PP were used as matrix materials: i) $\beta$ form of isotactic PP homopolymer (TIPPLEN H388F, TVK Nyrt., Tiszaújváros, Hungary); ii) random PP copolymer (TIPPLEN R351F TVK Nyrt., Tiszaújváros, Hungary), and iii) $\beta$ form of the latter. The manufacturing and properties of the matrix films was detailed elsewhere [21]. The melting temperature value of the $\beta$-modification was clearly below that of the corresponding $\alpha$-version, as expected.

\subsection{Composite preparation}

The matrix films (9 layers) and the reinforcing woven fabrics (8 plies) were laminated according to film-stacking method. Since the properties of the fabrics showed some directional anisotropy, they were assembled adopting a cross-ply lay-up to make the resulting sheets orthotropic. Self-reinforced PP composite (SRPPC) sheets with a thickness of $2.5 \mathrm{~mm}$ and a nominal reinforcement (i.e. $\alpha$-PP fabric) content of $50 \mathrm{wt} \%$ (note that this reinforcing content is substantially lower than in case of the commercial products $\left(\mathrm{Curv}^{\circledR}\right.$, Pure $\left.^{\circledR}\right)$ ) were produced by compression moulding of a filmstacked package at 7 different processing temperatures. They are selected at $5-35^{\circ} \mathrm{C}$ above the relevant matrix melting temperature. For the latter the DSC melting peak was considered [21]. The consolidation process took place as follows: after heating up the moulds, the film-stacked package was inserted and held for $30 \mathrm{~s}$ without pressure and for $90 \mathrm{~s}$ under a pressure of $7 \mathrm{MPa}$, and then it was cooled to $50^{\circ} \mathrm{C}$ with a cooling rate of $7.5^{\circ} \mathrm{C} / \mathrm{min}$ and demoulded. It is noteworthy that the holding time at processing temperature was kept as short and low, respectively, as possible to prevent shrinkage (relaxation) of the fibres.

\subsection{Specimens and their testing}

Short-time flexural creep tests were performed using three-point bending mode at different temperatures, ranging from -20 to $80^{\circ} \mathrm{C}$, in a DMA Q800 apparatus (TA Instruments, New Castle, USA). In this temperature range, isothermal creep tests were run on the specimens with a stepwise temperature increment of $10^{\circ} \mathrm{C}$. Prior to the creep measurement, each specimen was equilibrated for 
$5 \mathrm{~min}$. at each temperature and then the flexural creep behaviour was tested for $30 \mathrm{~min}$, under a constant load of $5 \mathrm{MPa}$. Specimens of dimensions $60 \times 15 \times 2.5 \mathrm{~mm}^{3}$ (length $\times$ width $\times$ thickness) were used for creep tests. For creep studies, the average of three statistically relevant creep data has been reported.

\section{Results and discussion}

The flexural creep behaviour of $\beta$-rPP-based composites (compression moulded at different temperatures) as a function of time at different testing temperatures is shown in Figures 1-3. It can be clearly seen from the results that with increasing temperature the creep compliance increases (due to increasing polymer chain mobility). With increasing hot pressing temperature, the SRPPCs have higher resistance to creep, particularly at higher testing temperatures. Recall that with increasing hot pressing temperature the consolidation improves and at the highest processing temperature a significant transcrystalline layer forms between the reinforcement and the matrix [21]. Better consolidation provides better mechanical properties, e.g. flexural stiffness and decreases creep compliance.

Figure $4 \mathrm{a}$ and $4 \mathrm{~b}$ show the creep compliance of $\alpha$-rPP and $\beta$-PP at different processing temperatures (determined at $1000 \mathrm{~s}$ ), as a function of the testing temperature. It can be seen that between -20 and $30^{\circ} \mathrm{C}$, there is no significant change in the creep compliance of the SRPPCs with different degrees of consolidation. To compare the composite made at $T_{m}+5^{\circ} \mathrm{C}$ with the composite made at optimum temperature $\left(T_{m}+20^{\circ} \mathrm{C}\right)$ it can be concluded, that the creep compliance of the well consolidated composite decreases in the whole testing temperature range. Further increase of processing temperature caused no change in the consolidation, clear transcrystalline layer formed between matrix and reinforcement, which decreases further the creep compliance particularly above testing temperature of $30^{\circ} \mathrm{C}$. The same tendency can be observed for $\beta$-rPP composites as well.

The logarithm of time and temperature has similar effect (based on thermomechanical curves), what is the well known reduction scheme of time-temperature superposition. Therefore single-step short-term creep tests can be further analyzed by superposing

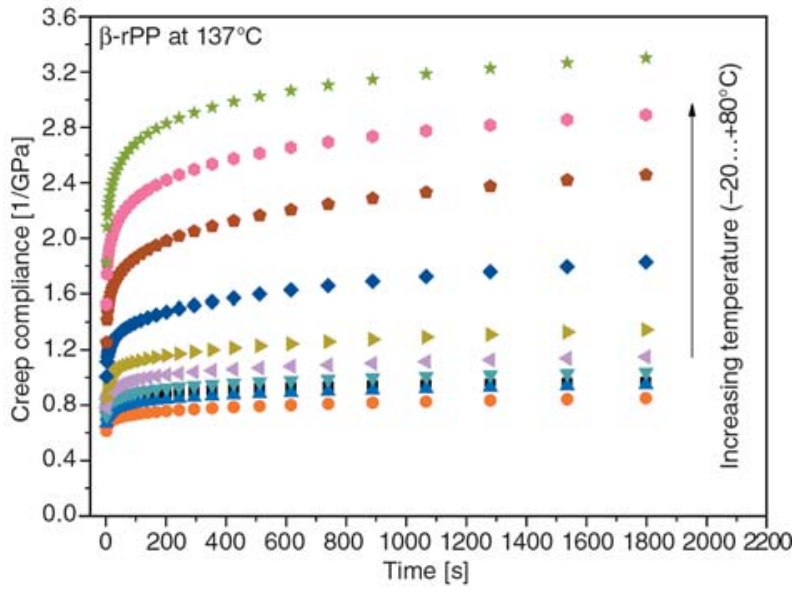

Figure 1. Creep compliance (between -20 and $80^{\circ} \mathrm{C}$ ) of $\beta$-rPP composite processed at $137^{\circ} \mathrm{C}$

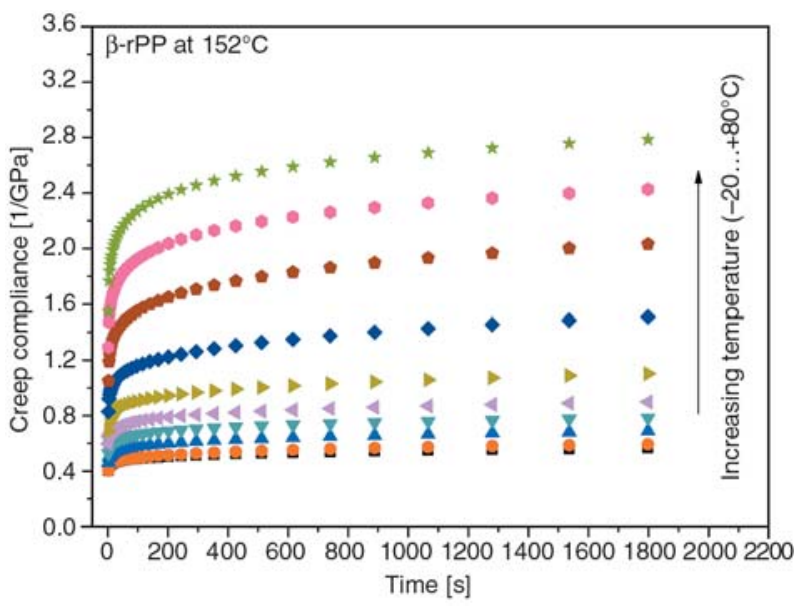

Figure 2. Creep compliance (between -20 and $80^{\circ} \mathrm{C}$ ) of $\beta$-rPP composite processed at $152^{\circ} \mathrm{C}$

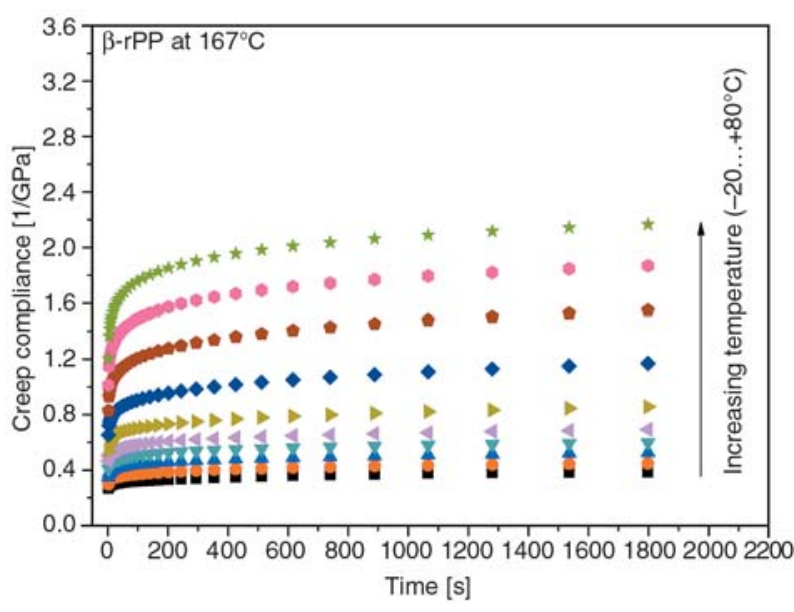

Figure 3. Creep compliance (between -20 and $80^{\circ} \mathrm{C}$ ) of $\beta$-rPP composite processed at $167^{\circ} \mathrm{C}$

(shifting) the compliance-time data onto master curves, which represent long-term creep behaviour of the material. Generally, from the master curves the behaviour of polymer can be traced over much wider periods of time than those determined exper- 

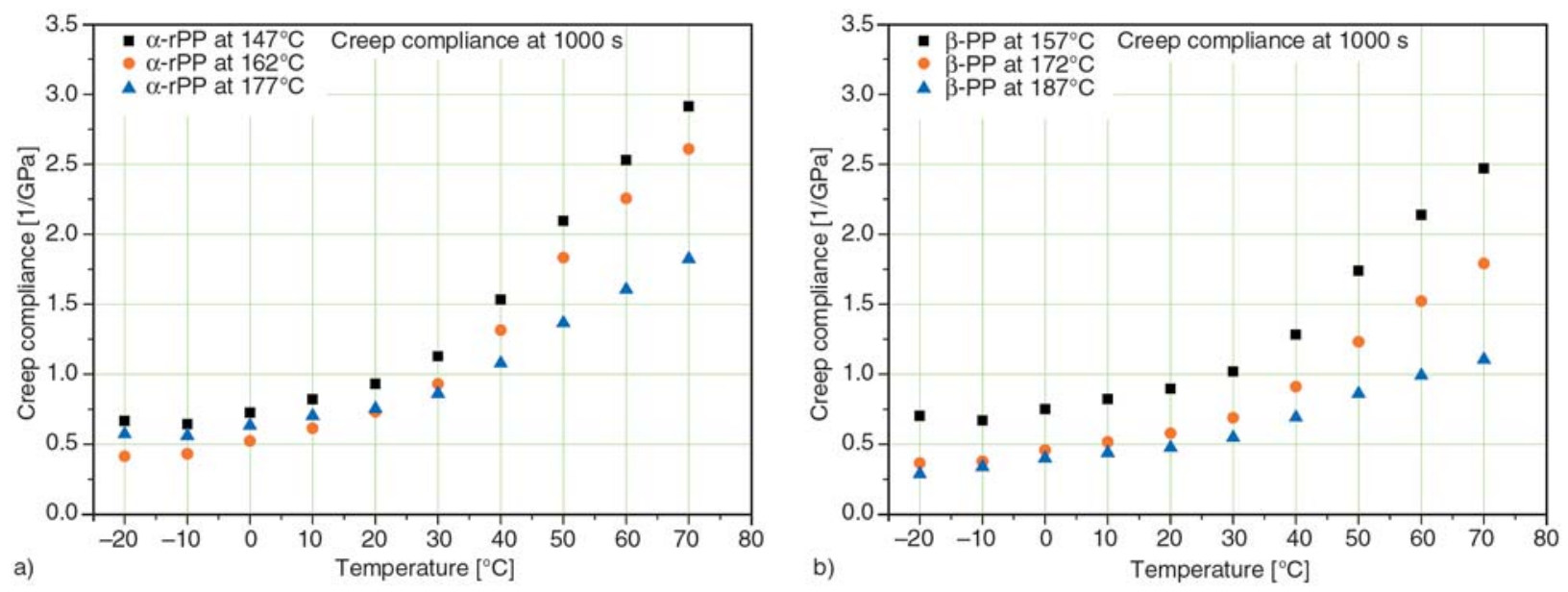

Figure 4. Creep compliance (at $1000 \mathrm{~s}$ ) of $\alpha$-rPP-based (a) and $\beta$-PP-based (b) composite

imentally. Figures 5-7 show the creep compliance master curves for different composites. The reference temperature was chosen at $30^{\circ} \mathrm{C}$ in each case. It can be clearly seen, that with increasing processing temperature the creep compliance decreases.

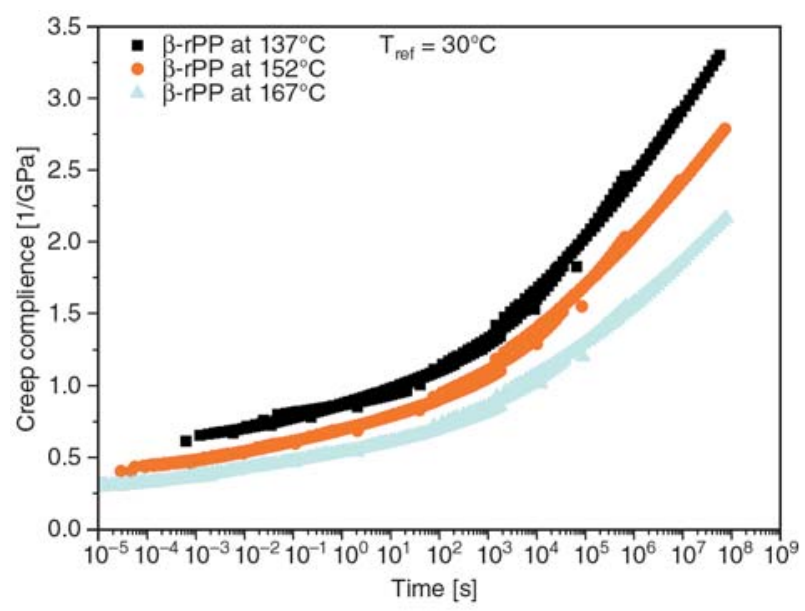

Figure 5. Creep compliance master curves of $\beta$-rPP-based composites

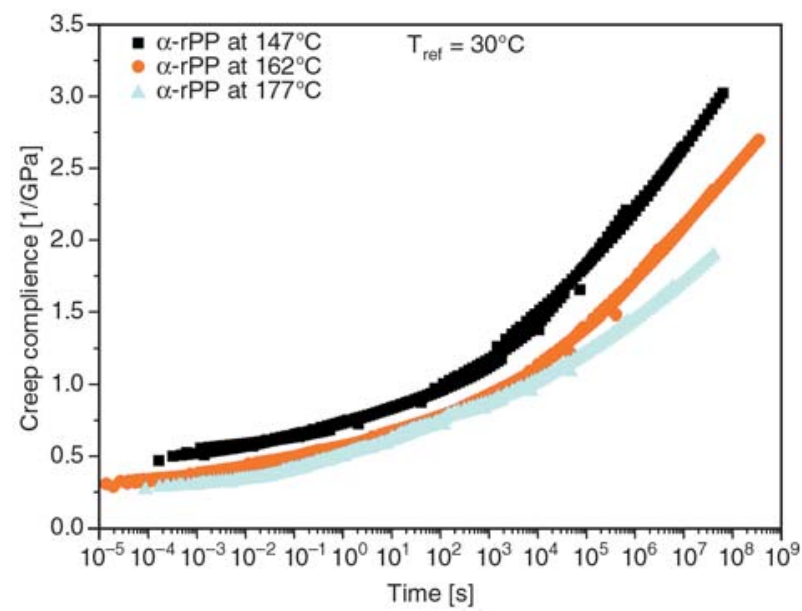

Figure 6. Creep compliance master curves of $\alpha$-rPP-based composites
Since the current creep test was performed under a small constant load (5 MPa) that can result in a small deformation in the SRPPCs, i.e. the stress is not high enough to cause significant elongation, therefore the consolidation and adhesion between matrix and reinforcement seem to influence the time-dependent deformation. So, the achieved results can be explained by the change of consolidation/adhesion of SRPPCs with increasing hot pressing temperature.

Since the main influence on the creep compliance is the consolidation and adhesion - concluded before; and the peel strength and density reflect well the consolidation, therefore good correlation can be expected between these parameters (these values were described in detail elsewhere [21]) and the creep compliance. Figure 8 shows the creep compliance as a function of peel strength. The value of creep compliance at $1000 \mathrm{~s}$ was chosen (according to $T_{r e f}=30^{\circ} \mathrm{C}$ ). With increasing peel strength (bet-

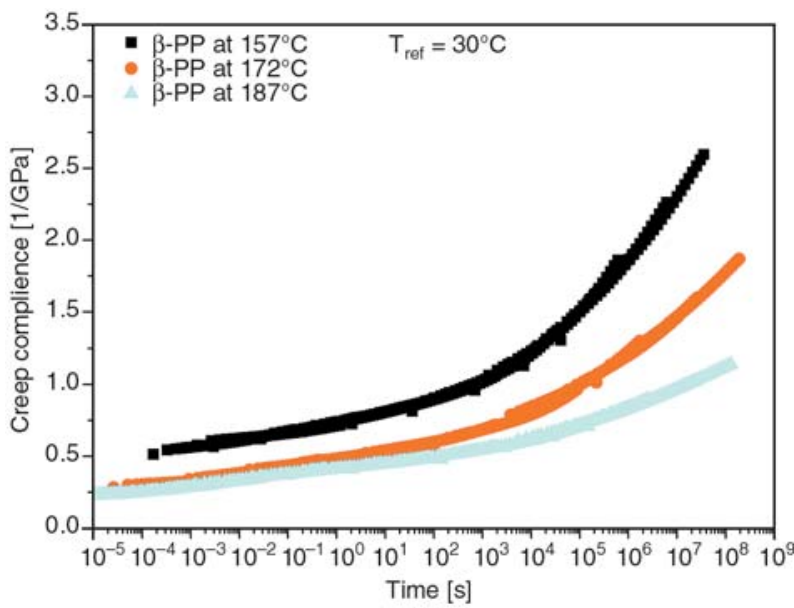

Figure 7. Creep compliance master curves of $\beta$-PP-based composites 


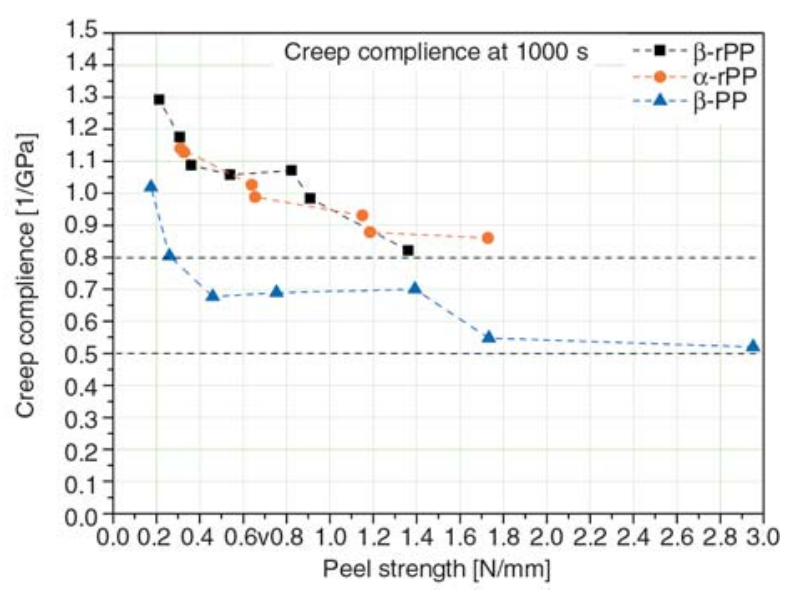

Figure 8. Creep compliance as a function of peel strength for different composites

ter consolidation), the creep compliance decreases as expected. It can be seen that each curve tends to a 'saturation' value, i.e. to a creep compliance limit, what might be the theoretical minimum for the given SRPPC. This value is $0.81 / \mathrm{GPa}$ for $\mathrm{rPP}$ based composites and $0.51 / \mathrm{GPa}$ for $\beta$-PP-based composites.

Many authors explain the creep compliance difference with the change of void content, i.e. with the change of density. Figure 9 shows the creep compliance as a function of density of different matrix based SRPPCs. The values of creep compliance at $1000 \mathrm{~s}$ were chosen as before. With increasing processing temperature, the density increases (better consolidation, lower void content), and the creep compliance decreases, as expected. The change is approximately linear, with good tendency.

The shift factor $a_{T}$ is the extent of shift along the time scale to merge the single creep curves meas-

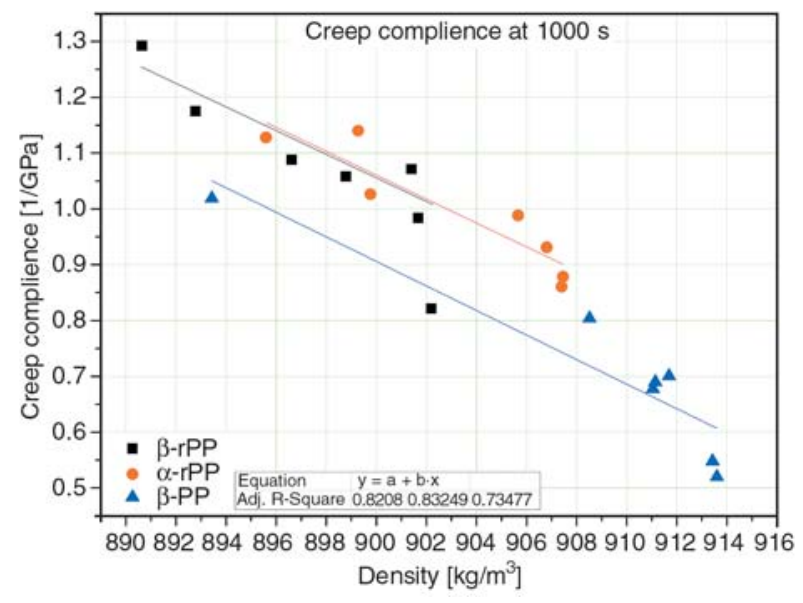

Figure 9. Creep compliance as a function of the density

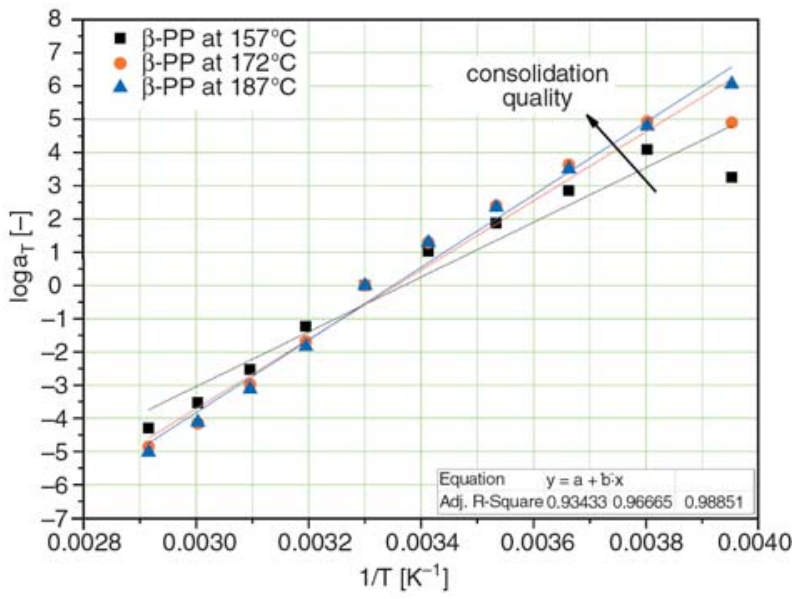

Figure 10. The shift factor follow the Arrhenius equation in the case of $\beta$-PP composite

ured at different temperatures into a master curve. The reference temperature was taken as $30^{\circ} \mathrm{C}$.

Because PP is a semicrystalline polymer, therefore it is expected to follow an Arrhenius equation for the major transitions. Figure 10 shows the shift factors as a function of inverse of temperature. It can well be seen, that the shift data can well be described by the Arrhenius equation. Note that, the $T_{g}$ of the composites is at $0^{\circ} \mathrm{C}$ in the case of iPP based composites and at $-15^{\circ} \mathrm{C}$ in the case of rPP based composites measured by DMA in our earlier work [8]. The linear regression lines are also shown in Figure 10.

One can see that with increasing consolidation (increasing processing temperature), the activation energy also increases. The activation energy of the deformation process was calculated from the slope of the regression curves (Equation (1)). The activation energy values are listed in Table 1 . This data are in harmony with other works [17, 20, 22, 23]. One can see that with increasing activation energy the creep compliance decreases.

Table 1. The activation energy of different SRPPCs

\begin{tabular}{|c|c|}
\hline & $\mathbf{E}_{\mathbf{a}}[\mathbf{k J} / \mathbf{m o l}]$ \\
\hline$\beta$-rPP at $137^{\circ} \mathrm{C}$ & 110.6 \\
\hline$\beta$-rPP at $152^{\circ} \mathrm{C}$ & 169.7 \\
\hline$\beta$-rPP at $167^{\circ} \mathrm{C}$ & 183.8 \\
\hline$\alpha$-rPP at $147^{\circ} \mathrm{C}$ & 114.4 \\
\hline$\alpha$-rPP at $162^{\circ} \mathrm{C}$ & 183.1 \\
\hline$\alpha$-rPP at $177^{\circ} \mathrm{C}$ & 185.0 \\
\hline$\beta$-PP at $157^{\circ} \mathrm{C}$ & 133.5 \\
\hline$\beta$-PP at $172^{\circ} \mathrm{C}$ & 175.4 \\
\hline$\beta$-PP at $187^{\circ} \mathrm{C}$ & 186.9 \\
\hline
\end{tabular}




\section{Conclusions}

The goal of this paper was to study the effect of consolidation effect on the creep behaviour of different SRPPCs. Single-step short-term creep tests were made on SRPPCs having different consolidation quality, and the creep compliance was superposed onto a master curve. Based on the results it can be concluded, that the creep resistance of the SRPPCs decreases with increasing testing temperature, due to the rising chain mobility at higher temperature. This effect is remarkable above room temperature. The creep resistance strongly depends on the consolidation quality of the composites. From the short-term flexural creep response, the long-term creep behaviour of the SRPPC could be predicted. The main effect on the creep compliance at applied low load is the consolidation. There are good correlations between creep compliance and density or peel strength. The theoretical creep compliance for best consolidated rPP based composite is app. $0.81 / \mathrm{GPa}$ and for $\beta$-PP composite is app. $0.51 / \mathrm{GPa}$. An Arrhenius type relationship describes well the time-temperature superposition data.

\section{Acknowledgements}

The authors want to thank the Hungarian Scientific Research Fund (OTKA K75117). T. Bárány is thankful for the János Bolyai Research Scholarship of the Hungarian Academy of Sciences.

\section{References}

[1] Hine P. J., Ward I. M., Jordan N. D., Olley R., Bassett D. C.: The hot compaction behaviour of woven oriented polypropylene fibres and tapes. I. Mechanical properties. Polymer, 44, 1117-1131 (2003). DOI: 10.1016/S0032-3861(02)00809-1

[2] Bhattacharyya D., Maitrot P., Fakirov S.: Polyamide 6 single polymer composites. Express Polymer Letters, 3, 525-532 (2009).

DOI: $\underline{10.3144 / \text { expresspolymlett.2009.65 }}$

[3] Alcock B., Cabrera N. O., Barkoula N. M., Loos J., Peijs T.: The mechanical properties of unidirectional all-polypropylene composites. Composites Part A: Applied Science and Manufacturing, 37, 716-726 (2006).

DOI: $10.1016 /$ j.compositesa.2005.07.002
[4] Alcock B., Cabrera N. O., Barkoula N-M., Spoelstra A. B., Loos J., Peijs T.: The mechanical properties of woven tape all-polypropylene composites. Composites Part A: Applied Science and Manufacturing, 38, 147-161 (2007).

DOI: 10.1016/j.compositesa.2006.01.003

[5] Houshyar S., Shanks R. A.: Morphology, thermal and mechanical properties of poly(propylene) fibre-matrix composites. Macromolecular Materials and Engineering, 288, 599-606 (2003).

DOI: $10.1002 / \mathrm{mame} .200300023$

[6] Houshyar S., Shanks R. A.: Mechanical and thermal properties of flexible poly(propylene) composites. Macromolecular Materials and Engineering, 291, 5967 (2006).

DOI: $10.1002 /$ mame.200500306

[7] Bárány T., Izer A., Czigány T.: On consolidation of self-reinforced polypropylene composites. Plastics Rubber and Composites, 35, 375-379 (2006). DOI: $10.1179 / 174328906 X 128234$

[8] Bárány T., Izer A., Karger-Kocsis J.: Impact resistance of all-polypropylene composites composed of alpha and beta modifications. Polymer Testing, 28, 176-182 (2009). DOI: $10.1016 /$ j.polymertesting.2008.11.011

[9] Houshyar S., Shanks R. A.: Tensile properties and creep response of polypropylene fibre composites with variation of fibre diameter. Polymer International, 53, 1752-1759 (2004). DOI: $10.1002 /$ pi.1569

[10] Houshyar S., Shanks R. A.: Mechanical and thermal properties of toughened polypropylene composites. Journal of Applied Polymer Science, 105, 390-397 (2007). DOI: $10.1002 / a p p .25034$

[11] Houshyar S., Shanks R. A., Hodzic A.: Tensile creep behaviour of polypropylene fibre reinforced polypropylene composites. Polymer Testing, 24, 257-264 (2005).

DOI: $10.1016 /$ j.polymertesting.2004.07.003

[12] Greco A., Musardo C., Maffezzoli A.: Flexural creep behaviour of PP matrix woven composite. Composites Science and Technology, 67, 1148-1158 (2007). DOI: 10.1016/j.compscitech.2006.05.015

[13] Acha B. A., Reboredo M. M., Marcovich N. E.: Creep and dynamic mechanical behavior of PP-jute composites: Effect of the interfacial adhesion. Composites Part A: Applied Science and Manufacturing, 38, 1507-1516 (2007).

DOI: $10.1016 /$ j.compositesa.2007.01.003

[14] Kim K. J., Yu W-R., Harrison P.: Optimum consolidation of self-reinforced polypropylene composite and its time-dependent deformation behavior. Composites Part A: Applied Science and Manufacturing, 39, 1597-1605 (2008). DOI: $10.1016 /$ j.compositesa.2008.06.005 
[15] Chartoff R. P.: Thermoanalytical instrumentation, techniques and methodology. in 'Thermoplastic polymers' (ed.: Turi E. A.) Academic Press, San Diego, 483-743 (1997).

[16] Ferry J. D.: Viscoelastic properties of polymers. Wiley, New York (1980).

[17] Banik K., Abraham T. N., Karger-Kocsis J.: Flexural creep behavior of unidirectional and cross-ply allpoly(propylene) $\left(\mathrm{PURE}^{\circledR}\right)$ composites. Macromolecular Materials and Engineering, 292, 1280-1288 (2007).

DOI: $\underline{10.1002 / m a m e .200700180}$

[18] Banik K., Karger-Kocsis J., Abraham T.: Flexural creep of all-polypropylene composites: Model analysis. Polymer Engineering and Science, 48, 941-948 (2008).

DOI: $10.1002 /$ pen.21041

[19] Chevali V. S., Dean D. R., Janowski G. M.: Flexural creep behavior of discontinuous thermoplastic composites: Non-linear viscoelastic modeling and timetemperature-stress superposition. Composites Part A: Applied Science and Manufacturing, 40, 870-877 (2009).

DOI: $10.1016 /$ j.compositesa.2009.04.012
[20] Dutta N. K., Edward G. H.: Generic relaxation spectra of solid polymers. 1. Development of spectral distribution model and its application to stress relaxation of polypropylene. Journal of Applied Polymer Science, 66, 1101-1115 (1997).

DOI: 10.1002/(SICI)1097-4628(19971107)66:6<1101 $\because$ AID-APP11>3.0.CO;2-4

[21] Izer A., Bárány T., Varga J.: Development of woven fabric reinforced all-polypropylene composites with beta nucleated homo- and copolymer matrices. Composites Science and Technology, 69, 2185-2192 (2009).

DOI: 10.1016/j.compscitech.2009.06.002

[22] Attalla G., Guanella I. B., Cohen R. E.: Effect of morphology on stress-relaxation of polypropylene. Polymer Engineering and Science, 23, 883-887 (1983). DOI: $\underline{10.1002 / \text { pen.760231605 }}$

[23] Alcock B., Cabrera N. O., Barkoula N-M., Reynolds C. T., Govaert L. E., Peijs T.: The effect of temperature and strain rate on the mechanical properties of highly oriented polypropylene tapes and all-polypropylene composites. Composites Science and Technology, 67, 2061-2070 (2007). DOI: $\underline{10.1016 / \mathrm{j} . c o m p s c i t e c h .2006 .11 .012}$ 